\title{
EVALUASI PROSES PENGOLAHAN DAGING RAJUNGAN PADA PT KML LOBUK KECAMATAN BLUTO KABUPATEN SUMENEP
}

\section{Evaluation Process Of Crab Meat Processing At PT. KML In Lobuk Village, Bluto Sub District, Sumenep District}

\author{
Eko Adi Sumitro ${ }^{1}$, Imam Hanafi ${ }^{2}$ \\ ${ }^{1,2}$ Program Studi Teknologi Hasil Pertanian Fakultas Pertanian Universitas Wiraraja \\ Jalan Raya Sumenep Pamekasan Km 5 Patean Sumenep; ekoadisumitro.@wiraraja.ac.id
}

\begin{abstract}
ABSTRAK
Salah satu proses pengawetan daging kepiting adalah menggunakan pasteurisasi. Berdasarkan bidang pengamatan, ada masalah pada daging kepiting yang dipasteurisasi pada musim panen kepiting, sehingga ada beberapa daging kepiting yang menimbun di pabrik mini yang menyebabkan ketidakseimbangan antara jumlah pengupas daging kepiting dan jumlah daging kepiting . Perlu strategi atau teknik yang baik untuk membuat kualitas daging kepiting tetap terjaga. Pada saat proses ini, daging kepiting disimpan dengan menggunakan es untuk daging kepiting mentah dan daging kepiting matang untuk menunggu proses pengupasan. Tujuan dari penelitian ini adalah untuk menilai perbedaan penyimpanan daging kepiting dalam keadaan mentah dan keadaan matang dengan menggunakan es di pabrik mini yang mempengaruhi kualitas daging kepiting yang telah dihasilkan sebelum proses pasteurisasi dalam daging kepiting organoleptik (penampilan, bau, rasa, dan tekstur), mikrobiologi (isi TPC, Coliform, dan E. coli), dan secara kimiawi (proksimat). Hasil penelitian ini menginformasikan sekutu organoleptik bahwa kualitas, mikrobiologi, dan hasil langsung dari daging kepiting mentah dan daging kepiting matang.
\end{abstract}

Kata kunci: Kualitas, Proses, Pengupasan, Kepiting.

\begin{abstract}
One of crab meat preservation process is used pasteurization. Based on the field observation, there is a problem in the crab meat pasteurized at crab harvest season, so that there are some crab meat hoarding in mini plant which cause of imbalance between amount of crab meat peeler and amount of crab meat. It needs good strategy or technique to make the quality of crab meat stay awake. At this process time, the crab meat is kept by using ice for raw state crab meat and ripe state crab meat to waiting the stripping process. The aim of this research is to assess the different storage of crab meat in the raw state and ripe state by using ice in mini plant which affect the quality of crab meat that have produced before pasteurization process in crab meat organoleptic (appearance, smell, taste, and texture), microbiology (content of TPC, Coliform, and E. coli), and chemically (proximate). The result of this research inform organoleptic ally that quality, microbiology, and proximate result of raw state crab meat and ripe state crab meat.
\end{abstract}

Keywords: Quality, Process, Stripping, Crab. 


\section{PENDAHULUAN}

Salah satu potensi kekayaan Negara Indonesia yaitu wilayah laut, daratan, bumi dan kekayaan alam lainnya. Serta potensi sumber daya alam yang begitu besar tersebut dapat memberikan kontribusi terhadap siklus kehidupan masyarakat Indonesia pada umumnya. Rajungan dan kepiting merupakan salah satu kekayaan laut yang dijadikan mata pencaharian oleh sebagian masyarakat yang terletak dipinggiran laut. Selain hasilnya yang sangat menjanjikan karena daging rajungan tersebut dijadikan bahan ekspor keberbagai penjuru dunia serta rajungan merupakan jenis makanan yang popular dan mempunyai harga cukup mahal.

Sekalipun pada dasarnya Rajungan aktif dipantai yang penuh lumpur serta berbatu dan disemak-semak, jenis binatang rajungan bukanlah jenis binatang yang secara efektif dalam berburu makan dengan bersama-sama melainkan binatang rajungan adalah pemburu makanan yang terpisah antara satu dan yang lain. Sehingga dalam penangkapan cukup memakan waktu agar tangkapan rajungan bisa mencapai yang diinginkan.

Beberapa kesulitan dalam penangkapan rajungan atau kepiting ini yaitu ketika memasuki musim bertelur, karena pada musim begitulah rajungan lebih memilih tempat yang aman untuk masamasa penetasan serta proses itu berjalan sangat lama hingga usia anak rajungan memasuki masa dewasa baru nelayan menangkap rajungan kembali, sepintas terlihat menggiurkan hasil yang didapat ketika hasil tangkapan rajungan melimpah ternyata disisi yang lain para nelayan juga memiliki kekhawatiran-kekhawatiran tertentu mengingat rajungan yang bermasa.

Berbudidaya rajungan ini merupakan usaha yang terkesan menjanjikan, dalam usaha proses pengolahan daging rajungan berpotensi agar dapat dikembangkan yang berada di Desa Lobuk telah berlangsung sejak tahun 2002 hingga 2018. Didalam melakukan produksinya PT KML desa Lobuku seringkali mengalami pasang surut (baik dalam segi penginkatan maupun penurunan) didalam melakukan kerjasama produksinya.

\section{METODE PENELITIAN}

Jenis penelitian yang dilakukan oleh peneliti lebih lebih mendekati kemetode Kuantitatif agar pendekatanpendekatan dilakukan bersifat Deskriptif, maksud dari penelitian kuantitatif adalah penelitian yang mendekati pada hal yang lebih sistematis, tersusun,terencana serta terstruktur dengan baik danjelas. mulai dari awal rencana penelitian hinggga sampai pada pembuatan kerangka penelitian. Menurut sugiyona (2013), jenismetode penelitian kuantitatif ini lebih mendekati pada penelitian yang berdasarkan pada filsafat positivism, metode ini seringkali digunakan dalam meneliti populasi atau pada sampel-sampel tertentu. Teknik pengumpulan data dalam hal ini peneliti menggunakan Wawancara dengan salah satu karyawan beserta pimpinan KML LOBUK. Pada sesi wawancara tersebut tentunya peneliti sudah mempersiapkan pertanyaan-pertanyaan yang dikemas dari rumah atau kampus jauh hari sebelum melakukan pertemuan di perusahaan tersebut, dengan mempersiapkan segala sesuatunya dalam bentuk jawaban yang tentunya sudah dipersiapkan oleh peneliti.(Sugiyono;194-195). Selanjutnya 
menggunakan metode Angket atau Kuisioner dengan harapan tindakan tersebut dapat menjadi teknik pada pengumpulan data dengan menggunakan sistem memberikan persiapan-persiapan pertanyaan agar nantinya pihak KML LOBUK dapat menjawabnya. Pada pertemuan ini peneliti dan pihak perusahaan melakukan pertemuan secara tertutup sehingga responden tinggal memilh jawaban yang disediakan oleh peneliti.

Dalam pencarian data penelitian peneliti mencari data secara langsungdari obyek penelitian perorangan, kelompok, dan organisasi(Ruslan,2008). Cara mendapatkan data ini baik dengan cara wawancara langsung kepada responden (pimpinan perusahaan, bagi yang berweang), dengan kusioner, pengumpulan angket, dan lainlain. Informasi data ini telah direncanakan dengan vareabel, indicator serta item yang telah ditentukan untuk memenuhi data yang diinginkan. Berikut adalah data Primer. Selanjutnya adalah data skunder, yang dimaksud data skunder tersebutadalah langkah-langkah peneliti dalam memperoleh data yang akurat dari beberapa karyawan dan pihak perusahaan pada KML LOBUK. (Ruslan,2008). Sumber tersebut juga dapat diartikan sebagai data yang bersumber dari informasi yang tidak langsung, misalnya seperti mengumpulkan informasi data melalui laporan perusahaan yang telah diterbitkan, jurnal penelitian mengenai perusahaan/instansi terkait, survey public mengenai perusahaan terkait dan lain-lain.

Dalam teknis analisis data kali ini setelah data diperoleh dari PT KML Lobuk dan dikumpulkan, maka langkah selanjutnya data tersebut dianalisis. Teknik analisis data bertujuan agar peneliti dapat dan mampu memahami segala persoalan diperusahaan sehingga peneliti bisa menggambarkan segala bentuk kekurangan dan persoalan- persoalan mengenai kendala dalam penentuan kualitas barang.Sehingga analisis data yang digunakan pada penelitian ini adalah menggunakan pendekatan kuantitatif, yaitu dengan menggunakan perhitungan releven terhadap masalah yang diteliti.Adapun alat analisis yang digunakan adalah menggunakan alat metode analisis deskriptif

\section{HASIL DAN PEMBAHASAN}

Dari beberapa penjelasan mengenai Hasil uji mutu daging rajungan pada mini plant sehingga Uji mutu yang dilakukan terhadap rajungan harus pada penyimpanan yang baik. Baik-dalam kondisi mentah maupun kondisi yang matang harus menggunakan pendingin (es) hal tersebut menggunakan teori dengan skala 1:1 hingga selama kurang lebih 12 jam. Pembahasan Daging rajungan tersebut pengujian mutunya menggunakan pengukusan serta pengupasan. Yang di dasarkan pada uji mutu daging selama penelitian diterima dilakukan dua hal hasil uji mutu daging rajungan yaitu secara subjektif dan obejktif.

Bentuk pengujian hasil dan kualitas harus ditangani oleh karyawan yang memahami betul tentang mini plant. Karena hasil daging yang sudah melewati plant harus lebih baik kualitasnya dari standart SNI, karena perusahaan KML LOBUK tentunya menginginkan hasil daging yang sudah melewati mini plant mempunyai kualitas yang sempurnah sehingga daging yang menjadi barang impor dapat tersampaikan ke konsumen sesuai harapan. Dalam Hal ini terkadang seringkali mengakibatkan penilaian pada pengujian organoleptik daging rajungan lebih rendah dari SNI. Berikut adalah Hasil dari pengamatan yag dilakukan oleh peneliti secara organoleptik pada mini plant. 
Tabel 1. Uji Organoleptik Di Mini Plant

\begin{tabular}{|c|c|c|c|}
\hline \multirow{2}{*}{$\begin{array}{c}\text { Penyimpanan/ } \\
\text { Ulangan }\end{array}$} & \multicolumn{3}{|c|}{$\begin{array}{c}\text { Mutu daging rajungan } \\
\text { secara organoleptik }\end{array}$} \\
\cline { 2 - 4 } & Jumbo & Reguler & $\begin{array}{c}\text { Claw } \\
\text { meat }\end{array}$ \\
\hline $\begin{array}{c}\text { Kondisi } \\
\text { mentah }\end{array}$ & & & \\
\hline 1 & 6,00 & 5,75 & 5,50 \\
\hline 2 & 6,25 & 6,25 & 6,00 \\
\hline 3 & 6,00 & 5,75 & 5,75 \\
\hline 4 & 6,50 & 6,00 & 5,00 \\
\hline Rata-rata & 6,19 & 5,94 & 5,85 \\
\hline $\begin{array}{c}\text { Kondisi } \\
\text { matang }\end{array}$ & & & \\
\hline 1 & 6,50 & 6,00 & 6,25 \\
\hline 2 & 7,00 & 6,50 & 6,25 \\
\hline 3 & 7,00 & 6,50 & 6,25 \\
\hline 4 & 6,50 & 6,25 & 6,25 \\
\hline Rata-rata & 6,75 & 6,31 & 6,25 \\
\hline
\end{tabular}

Hasil penyimpanan daging pada mini plant dalam hal ini pada daging mentah 5,94 $\pm 0,24$ maupun yang matang $6,31 \pm 0,24$ serta probabilitas 0,069 . Pada penilaian hipotesis 1 dapat dirata-ratakan menjadi daging reguler yang tidak terdapat perselisihan pada organopoleptik pada penyimpanan daging mentah maupun daging yang matang justru malah dianggap sama.

Setiap daging yang melalui proses mini plant mempunyai karakter yang berbeda yaitu: penampakan daging tidak bagus, tidak bersih, tidak sama (skor 6); aroma tidak sedap - sangat sedap (nilai 6-7); hasil tidak bagus, tidak sempurah, tetap basah (skor6); serta tidak dapat membedakan aroma yang bagus (skor 5-6). karakter pada kedua penyimpanantersebut mempunyai hasil dengan skor yang sama, untuk membadakan keduanya yaitu pada rasa yang terkesan lebih manis (skor 6-7).

Kesamaan organoleptik daging dalam penyimpanan baik yang tersimpan dalam posisi mentah dan yang matang $(5,94$ serta 6,31) masih dibawah standarSNI. Pada
standarSNI No. 01-6929.1-2002, yang menjadi persyaratan pada penilaian dingin paling sedikit 7 , paling tidak harus utuh, kualitas warnanya daging tersebut harus berwarna putih susu, agak sedikit kuning; terlihat menarik, wangi daging rajungan nampak sekali bahwa daging tersebut sangat menarik rasa; manis, enak, renyah; serta bentuk serat terlihat.

Agar usaha yang dilakukan oleh perusahaan KML LOBUK tentang pengolahannya dapat mencapai ketentuan yang makasimal dengan aman pada taraf penilaian organoleptik sempurnah (paling sedikit 7) serta kualitasnya sesuai dengan standartSNI 01-6929.2-2002 diantaranya daging segar yang brlum mengalami pengolahahan, serta nelayan penangkap rajungan atau kepiting dapat memilah kualitas kepiting dari kondisi perairannya. Karena hasil tangkapan nelayan yang disetor ke PT KML LOBUK melalui proses mini plant sehingga hasilnya dapat terlihat dengan jelas.

Tabel 2. Hasil Mini Plant daging kepiting.

\begin{tabular}{|c|c|c|c|}
\hline \multirow{2}{*}{$\begin{array}{c}\text { Penyimpanan } \\
\text { / ulangan }\end{array}$} & \multicolumn{3}{|c|}{$\begin{array}{c}\text { Mutu daging rajungan } \\
\text { secara organoleptik }\end{array}$} \\
\cline { 2 - 4 } & $\begin{array}{c}\text { Jumb } \\
\text { o }\end{array}$ & $\begin{array}{c}\text { Regule } \\
\text { r }\end{array}$ & $\begin{array}{c}\text { clawmea } \\
t\end{array}$ \\
\hline $\begin{array}{c}\text { Kondisi } \\
\text { mentah }\end{array}$ & & & \\
\hline 1 & 5,75 & 5,50 & 5,50 \\
\hline 2 & 6,25 & 6,00 & 6,00 \\
\hline 3 & 6,00 & 5,75 & 5,75 \\
\hline 4 & 6,25 & 6,00 & 6,00 \\
\hline Rata-rata & 6,06 & 5,81 & 5,81 \\
\hline $\begin{array}{c}\text { Kondisi } \\
\text { matang }\end{array}$ & & & \\
\hline 1 & 6,50 & 6,00 & 6,00 \\
\hline 2 & 7,00 & 6,25 & 6,25 \\
\hline 3 & 7,00 & 6,50 & 6,25 \\
\hline 4 & 6,50 & 6,25 & 6,25 \\
\hline Rata-rata & 6,75 & 6,25 & $\mathrm{I} 6,19$ \\
\hline
\end{tabular}


Berdasarkan tabel diatas dapat dilihat bahwa hasil daging yang tersimpan dalam keadaan mentah 6,06 $\pm 0,24$ serta daging yang tersimpan dalam keadaan matang matang 6,75 $\pm 0,29$, terhitung 3,667 dalam propabilitas 0,01. Hal teresbut dapat diartikan pada hipotesis 1 di tolak, hipotesis 2 diterima pada takaran yang sangat besar.

Kepiting dengan ukuran besar yang tersimpan dalam keadaan belum dikukus penampakannya sangat bagus (kusam dan cukup cemerlang), sedikit tidak hiegenis, berlemi-sedikit, dan tidak mempunyai keseragaman, bau mendekati dan cukup segar, tetapi juga ada ketidak sempurnaan, dan membasah.

Beberapa percobaan seringkali dicoba secara berkali-kali oleh PT KML LOBUK dengan menyimpan dagin rajungan dengan ukuran besar pada mini plant aga mampu menemukan hasil yagn sesuai dengan keinginan konsumen serta keawetan dalam proses waktu pengiriman secara maksimal.

Namun PT KML LOBUK terus melakukan ujji cobanya dari plant ke mini plant dengan durasi waktu kurang lebih 1 jam-an maka hasil organoleptik dengan ukuran yang sangat besar sedikit mengalami penurunan, sedangkan pada proses penyimpanan daging yang matang matang tidak mengalami perubahan (tetaap) perlakuan tersebut disebabkan lalainya karyawan sehingga es tidak sesuai dan tidak cermat5, hany aberdasarkan perkiraan. Persoalan yang sering terjadi adalah kurangnya es di mini plant pada saat pengiriman.

Untuk menjaga kualitas pengiriman maka perlu perusahaan memperhatikan tata cara pengepakan yang langkah-langkahnya harus disesuaikan dengn SOP, yaitu diantaranya:

- Harus dikemas dengan rekomendasi berupa wadah plastic (toples)
- memperhatikan sirkulasi serta lubanglubang pembuangan

- sanitasi pada toples

- pengklasifikasian daging harus jelas

- banyaknya daging disesuaikan dengan wadahnya

- kualitas es diperhatikan

- ea yang digunakan tidak merupakan es bekas

- tingkat kehati-hatian harus ditingkatkan dalam penyusunan barang

\section{KESIMPULAN}

Berdasarkan hasil penelitian pada PT KML Desa Lobuk tentang Evaluasi Proses Daging Rajungan dapat ditarik suatu kesimpulan sebagai berikut.

1. Tingkat padatnya pekerjaan PT KML masih bergantung hasil tangkapan nelayan yang juga hal itu bergantung pada musim serta cuaca

2. Berdasarkan penelitian yang dilakukan terkait dengan penyimpanan daging rajungan pada mini plant dalam ukuran yang bervariasi baik kondisi mentah maupun matang sudah tergolong maksimal

3. Tes uji hasil kualitas sudah ditangani oleh karyawan yang sudah berpengalaman dan sudah teruji bisa lebih baik dan sesuai standart SNI

4. Dari beberapa kejadian sewaktu pengiriman daging kepiting atau rajungan seharusnya dijadikan hal yang bersifat negatif sekalipun pengaruh positifnya tidak signifikan terhadap persaingan pemasaran.

\section{DAFTAR PUSTAKA}

Balai Bimbingan dan Pengujian Mutu Hasil Perikanan, 1995, Laporan Pengembangan Pengolahan Kepiting Bakau dan Rajungan, Direktorat Jenderal Perikanan, Jakarta. 
Harris, R. S. dan Karmas, E., 1989, Evaluasi Gizi pada Pengolahan Bahan Pangan, Institut Teknologi Bandung, Bandung.

Jupri, A., 1996, Pedoman Pemeriksaan Rajungan Kaleng Pasteurisasi, PT. Phillips Seafood Indonesia, Pemalang, Jawa Tengah.

Juwana, S. dan Kasijan Romimohtarto, 2000, Rajungan Perikanan, Cara Budidaya dan Menu Masakan, Djambatan, Jakarta.

Moeljanto, R., 1982, Pendinginan dan Pembekuan Ikan, PT. Penebar Swadaya, Jakarta. 